\title{
Кремниевые светодиоды с люминесценцией (113) дефектов
}

\author{
(C) А.Е. Калядин, К.Ф. Штельмах, П.Н. Аруев, В.В. Забродский, \\ К.В. Карабешкин, Е.И. Шек, Н.А. Соболев \\ Физико-технический институт им. А.Ф. Иоффре Российской академии наук, \\ 194021 Санкт-Петербург, Россия \\ ฯ E-mail: nick@sobolev.ioffe.rssi.ru
}

Поступила в Редакцию 10 февраля 2020 г.

В окончательной редакции 17 февраля 2020 г.

Принята к публикации 17 февраля 2020 г.

\begin{abstract}
С применением имплантации ионов кислорода с энергией 350 кэВ и дозой $3.7 \cdot 10^{14} \mathrm{~cm}^{-2}$ и последующего отжига в хлорсодержащей атмосфере при $700^{\circ} \mathrm{C}$ в течение 1 ч изготовлены кремниевые светодиоды с люминесценцией (113) дефектов. Электролюминесценция исследована в широких диапазонах температуры и мощности накачки. Во всех спектрах доминирует линия (113) дефектов. Температурная зависимость интенсивности линии зависит от мощности накачки в области низких температур: при низких плотностях тока наблюдается возгорание интенсивности с энергией 25 мэВ, а с ростом тока увеличения интенсивности не наблюдается. При более высоких температурах происходит гашение интенсивности с энергией 59 мэВ независимо от плотности тока. С ростом температуры положение максимума линии (113) дефекта смещается на такую же энергию, как ширина запрещенной зоны, а полуширина линии растет линейно.
\end{abstract}

Ключевые слова: (113) дефекты, кремний, светодиоды, электролюминесценция.

DOI: 10.21883/FTP.2020.06.49389.9369

\section{1. Введение}

Развитие кремниевой оптоэлектроники нуждается в создании инфракрасных светодиодов с разной длиной волны на основе монокристаллического кремния. Для диапазона длин волн 1.5-1.7 мкм, соответствующего второму окну прозрачности кварцевых волокон, уже изготовлены светодиоды с люминесценцией редкоземельных ионов $\mathrm{Er}^{3+}[1,2]$ и так называемой дислокационной люминесценцией, обусловленной протяженными дефектами $[3,4]$. Они характеризуются высокой интенсивностью электролюминесценции при комнатной температуре. Для диапазона длин волн 1.3-1.4 мкм, соответствующего первому окну прозрачности, светодиоды пока не разработаны. В последнее время при создании светоизлучающих структур предпринимались попытки использовать в качестве люминесцентных центров линию с длиной волны $\sim 1.37$ мкм, которая наблюдалась в ряде образцов монокристаллического кремния, содержащего так называемые (113) дефекты $[5,6]$. На начальном этапе исследований доминировала точка зрения, что протяженные (113) дефекты представляют собой скопления собственных межузельных атомов со структурой, отличающейся от структуры дислокационных диполей и петель [5]. Позднее было показано, что в формировании (113) дефектов принимают участие и вакансии [6]. Предположение о взаимосвязи (113) дефектов, сформированных в процессе двухступенчатого длительного отжига кремния, выращенного методом Чохральского, и линии излучения на длине волны 1.37 мкм было высказано в работе [7]. Исследования образцов, имплантированных ионами $\mathrm{Si}^{+}$с последующим отжигом в инертной атмосфере [8-10], или имплантированных ионами $\mathrm{O}^{+}$с последующим отжигом в хлорсодержащей атмосфере [11-13], методами высокоразрешающей электронной микроскопии и фотолюминесценции подтвердили, что линия 1.37 мкм принадлежит (113) дефекту. Также было показано, что фотолюминесценция наблюдается и при температурах выше азотной $(>77 \mathrm{~K})[7,9,13]$. Это предполагало проведение исследований по созданию светодиодов с люминесценцией (113) дефектов. Однако, насколько нам известно, такой информации в литературе нет. В настоящей работе исследованы зависимости основных параметров линии электролюминесценции (113) дефектов (интенсивности, положения максимума линии и ее полуширины) от температуры измерения и плотности тока в образцах светодиодов на основе кремния, имплантированного ионами кислорода.

\section{2. Экспериментальные условия}

В исходные пластины кремния $n$-типа проводимости, выращенного методом Чохральского с удельным сопротивлением $4.5 \mathrm{OM} \cdot \mathrm{cm}$, для формирования $p^{+}-n$-перехода проводилась диффузия бора из газовой фазы [4]. Поверхностная концентрация бора и глубина расположения $p^{+}-n$-перехода равнялись $\sim 10^{20} \mathrm{~cm}^{-3}$ и $\sim 50 \mathrm{Hм}$ соответственно. Ионы кислорода с энергией 350 кэВ и неаморфизующей дозой $3.7 \cdot 10^{14} \mathrm{~cm}^{-2}$ имплантировались со стороны $p^{+}$-слоя. Имплантация проводилась при комнатной температуре под углом $7^{\circ}$, чтобы избежать эффекта каналирования. Основная часть ионов кислорода находилась значительно глубже $p^{+}-n$-перехода, поскольку проецированная длина пробега ионов кислорода, рассчитанная с помощью программы SRIM [14], равнялась 790 нм. Последующий отжиг, в ходе кото- 
рого отжигались введенные при имплантации дефекты и формировались люминесцентные центры, проводился при температуре $700^{\circ} \mathrm{C}$ в течение 1 ч в хлорсодержащей атмосфере, представляющей собой поток кислорода, насыщенный парами четыреххлористого углерода с молярной концентрацией $1 \%$. Как показали исследования с помощью просвечивающей электронной микроскопии и фотолюминесценции, в таких светоизлучающих структурах доминировали структурные (113) дефекты и принадлежащие им люминесцентные центры с длиной волны 1.37 мкм [13]. Омические контакты формировались напылением алюминия и его вжиганием при $420^{\circ} \mathrm{C}$. Травлением боковой поверхности образцов в смеси плавиковой и азотной кислот заканчивалось изготовление диодных $p^{+}-n$-мезаструктур. Площадь структур равнялась 3.7 мм² $^{2}$ Спектры электролюминесценции измерялись на автоматизированном спектрометре на основе монохроматора МДР-23 и неохлаждаемого фотодиода InGaAs с разрешением 5 нм. Образец помещался в криостат, обеспечивающий температуру измерений в диапазоне $4.2-300 \mathrm{~K}$ с точностью $\pm 0.2 \mathrm{~K}$. Электролюминесценция возбуждалась прямоугольными импульсами тока длительностью $15 \mathrm{Mc}$, амплитудой до $160 \mathrm{мA} \mathrm{и} \mathrm{частотой}$ 32 Гц. Излучение собиралось с боковой поверхности диодных структур. Параметры линии электролюминесценции (113) дефектов определялись путем их аппроксимации кривыми Гаусса.

\section{3. Экспериментальные результаты и их обсуждение}

Спектры электролюминесценции (EL) исследуемых диодных структур при температурах измерения $T=30-170 \mathrm{~K}$ и плотности тока $4.61 \mathrm{~A} / \mathrm{cm}^{2}$ приведены на рис. 1 для диапазона длин волн 1150-1550 нм.

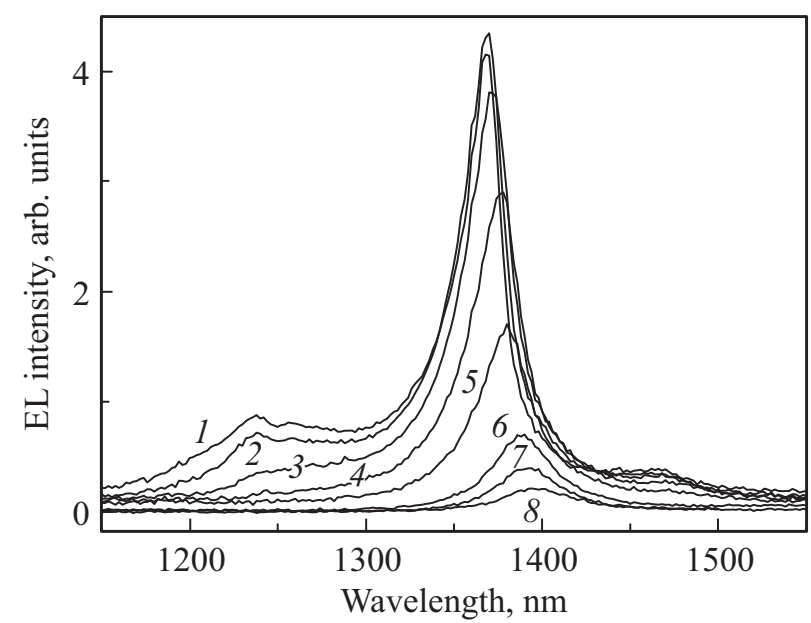

Рис. 1. Спектры электролюминесценции светодиодных структур при плотности тока $4.61 \mathrm{~A} / \mathrm{cm}^{2}$ и температурах измерения, $T$, К: $1-30,2-50,3-70,4-90,5-110,6-130$, $7-150,8-170$.

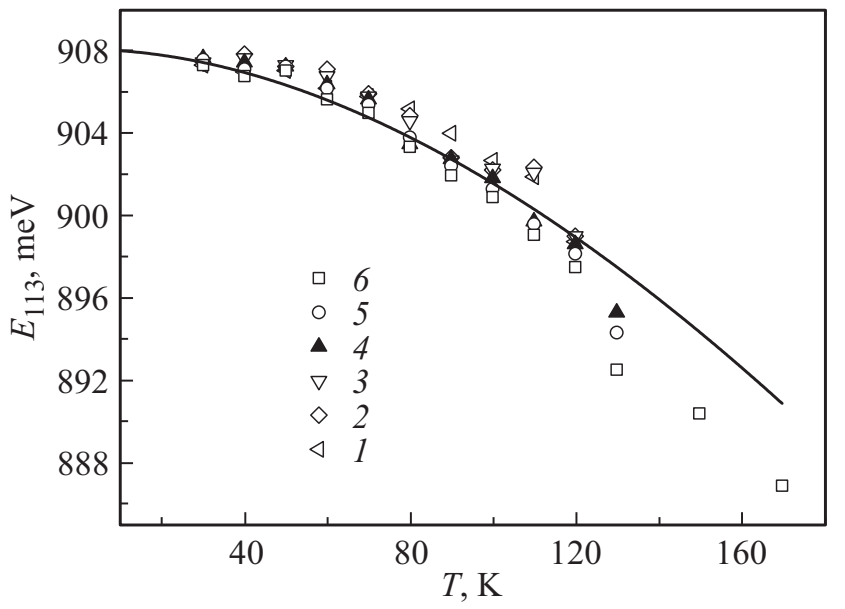

Рис. 2. Температурные зависимости положения максимума линии электролюминесценции (113) дефектов при разной плотности тока, $\mathrm{A} / \mathrm{cm}^{2}: 1-0.58,2 ; 2-0.86,3-1.73$, $4-2.59,5-3.46,6-4.61$. Сплошная линия аппоксимация формулой (2).

Доминирующая в спектрах линия принадлежит (113) дефектам [13]. При фиксированной температуре измерения положение максимума этой линии не зависит от плотности тока, а его амплитуда монотонно увеличивается с ростом тока. Полуширина линии при увеличении тока не изменяется. Характерной особенностью линии (113) дефектов является наличие асимметричного хвоста со стороны меныших длин волн $[8,12]$. В спектре также наблюдаются две линии с длинами волн $\sim 1230$ и $\sim 1470$ нм. Их интенсивность при низких температурах существенно меньше, чем у линии (113) дефекта, они исчезают с ростом температуры выше $70 \mathrm{~K}$ и поэтому в данной работе не рассматриваются.

Экспериментальные значения положений максимумов линии электролюминесценции (113) дефектов в зависимости от температуры в диапазоне плотностей тока $0.58-4.61 \mathrm{~A} / \mathrm{cm}^{2}$ приведены на рис. 2. С ростом температуры наблюдается сдвиг линии люминесценции в длинноволновую сторону. Температурная зависимость ширины запрещенной зоны кремния (в мэВ) описывается формулой [15]

$$
E_{g}(T)=1169-0.49 T^{2} /(T+655),
$$

где $T$ - температура в К. Аппроксимация приведенных на рис. 2 зависимостей для всей совокупности плотностей тока (сплошная кривая) показала, что экспериментальная температурная зависимость положения максимума линии электролюминесценции (113) дефектов $\left(E_{113}\right)$ достаточно хорошо описывается зависимостью

$$
E_{113}(T)=907-0.49 T^{2} /(T+655)=E_{g}(T)-\Delta E,
$$

где $\Delta E$ не зависит от температуры. Величина $\Delta E$, определенная из наших измерений, составляет $(262 \pm 1)$ мэВ. 


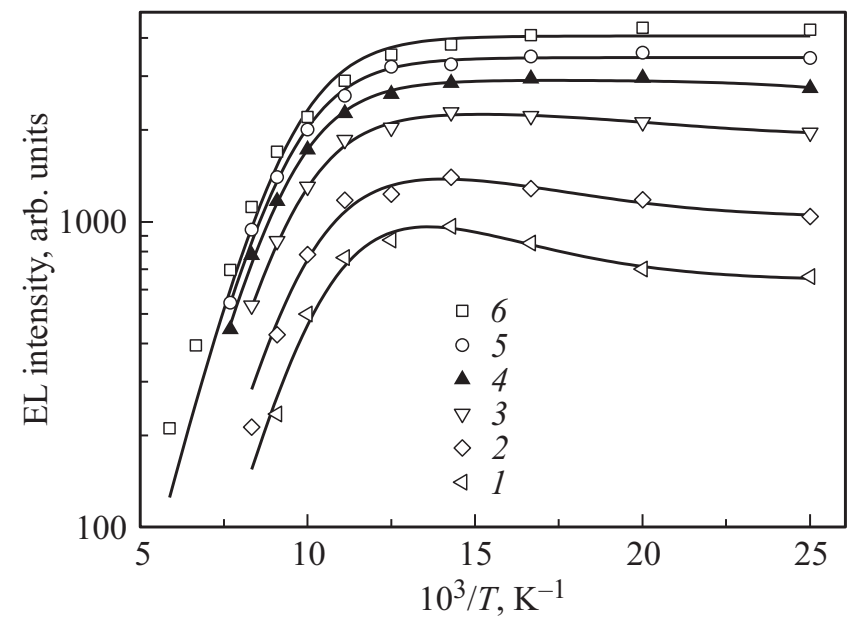

Рис. 3. Зависимости интенсивности линии электролюминесценции (113) дефектов от обратной температуры при разной плотности тока, $\mathrm{A} / \mathrm{cm}^{2}: 1-0.58,2-0.86,3-1.73,4-2.59$, $5-3.46,6-4.61$. Сплошные линии - аппроксимирующие кривые согласно (3).

Погрешность определения $\Delta E$ меньше аппаратурной погрешности измерений. Формула (2) показывает, что с ростом температуры энергетическое положение (113) дефектов смещается параллельно уменьшению ширины запрещенной зоны кремния. Измеренная температурная зависимость положения максимумов линии электролюминесценции (113) дефектов совпадает с аналогичной зависимостью линии фотолюминесценции этих дефектов [13]. Отметим, что ранее для линий дислокационной люминесценции $D 1$ и $D 2$ (принадлежащих другим протяженным структурным дефектам) также наблюдалось уменьшение значений их энергетических положений синхронно с шириной запрещенной зоны кремния при увеличении температуры [3,16-18].

Как видно из рис. 1, интенсивность линии электролюминесценции (113) дефектов с ростом температуры измерения до $\sim 70 \mathrm{~K}$ изменяется незначительно, а при дальнейшем росте температуры уменьшается достаточно быстро, при этом регистрируется вплоть до $170 \mathrm{~K}$. На рис. 3 приведены экспериментальные значения (точки) интегральной интенсивности $(I)$ линии люминесценции (113) дефекта от обратной температуры для плотностей тока в диапазоне $0.58-4.61 \mathrm{~A} / \mathrm{cm}^{2}$. Полученные зависимости хорошо описываются формулой [19]

$$
\begin{aligned}
I(T)= & I(0)\left\{1+C /\left[1+B \exp (-E / k T) \cdot T^{n}\right]\right\}^{-1} \\
& \times\left[1+D \exp (-W / k T) \cdot T^{n}\right]^{-1},
\end{aligned}
$$

где $W$ и $E-$ энергии возгорания и гашения люминесценции соответственно, $B, C$ и $D-$ параметры модели, зависящие от плотности тока, $k-$ постоянная Больцмана, $n=1.5$. Аппроксимирующие кривые также приведены на рис. 3 (сплошные линии). Энергии возгорания и гашения электролюминесценции равны $(25 \pm 5)$ и $(59 \pm 8)$ мэВ соответственно. Нижние три кривые представляют собой хорошо известные зависимости, когда с ростом температуры сначала наблюдается возгорание интенсивности люминесценции, а затем ее гашение [19]. Возгорание интенсивности люминесценции объясняется тем, что экситоны при низких температурах захватываются на мелкие центры, с ростом температуры высвобождаются, диффундируют, далее происходит их захват и излучательная рекомбинация на люминесцентном центре. В нашем случае относительное возгорание интенсивности люминесценции линии (113) дефекта с ростом плотности тока от 0.58 до $1.73 \mathrm{~A} / \mathrm{cm}^{2}$ уменьшается и отсутствует при больших плотностях тока. Этот эффект можно объяснить следующим образом. При маленькой плотности тока концентрации мелких центров захвата и вводимых при пропускании тока экситонов соизмеримы, поэтому происходит значительное возгорание интенсивности люминесценции при термическом высвобождении экситонов. По мере того как концентрация вводимых экситонов начинает превышать концентрацию центров захвата и соответственно концентрацию термически освобождаемых экситонов, эффект возгорания интенсивности люминесценции ослабевает, и начиная с некоторых значений плотности тока участок возгорания не наблюдается. Гашение интенсивности электролюминесценции обусловлено деактивацией возбужденного состояния центра (113) и(или) появлением каналов безызлучательной рекомбинации. Как правило, этот процесс представляет собой многофононную безызлучательную рекомбинацию. Полученные значения энергий возгорания и гашения электролюминесценции хорошо совпадают со значениями соответствующих энергий в случае фотолюминесценции. Это означает, что при изготовлении мезасветодиодов (при формировании омических контактов и краевого контура) структура (113) дефектов и параметры принадлежащих им люминесцентных центров не изменяются. Насколько нам известно, температурная зависимость интенсивности электролюминесценции линии (113) дефектов нами исследовалась впервые. Существенным отличием от данных по фотолюминесценции является исчезновение участка возгорания интенсивности электролюминесценции с ростом плотности тока при низких температу$\operatorname{pax}[12,13]$.

Экспериментальные значения (точки) полуширины линии электролюминесценции (113) дефектов (полной ширины на половине высоты, FWHM) при разных температурах для плотности тока $4.61 \mathrm{~A} / \mathrm{cm}^{2}$ приведены на рис. 4. С ростом температуры полуширина увеличивается. Измеренная температурная зависимость FWHM (в нм), как и в случае фотолюминесценции, хорошо аппроксимируется линейной зависимостью (сплошная прямая на рис. 4)

$$
\mathrm{FWHM}=a T+b,
$$

где $a=0.143 \mathrm{Hм} / \mathrm{K}, b=22.2 \mathrm{Hм}$. При электролюминесценции наблюдается увеличение полуширины линии 


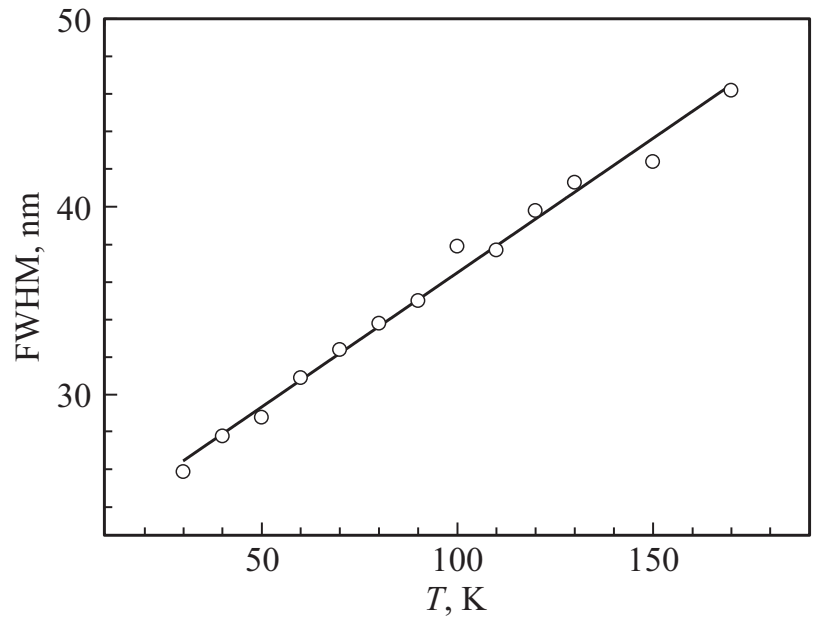

Рис. 4. Температурная зависимость полуширины линии люминесценции (113) дефектов (точки) и аппроксимация формулой (4) (сплошная линия).

(113) дефектов по сравнению с фотолюминесценцией: наклоны прямых (константа $a$ ) для обоих типов возбуждения люминесценции практически совпадают, а значение константы $b$ в случае электролюминесценции увеличилось в 1.7 раза [12]. Ранее уширение линий люминесценции с ростом температуры измерения наблюдалось для линий дислокационной люминесценции $D 1$ и $D 2$, так же сформированных с участием собственных межузельных атомов кремния [17].

\section{4. Заключение}

Впервые изготовлены светодиодные структуры с люминесценцией (113) дефектов. Создавались $p^{+}-n$-переходы с помощью диффузии бора, а (113) дефекты формировались в процессе имплантации ионов кислорода и последующего отжига. Исследованы зависимости основных параметров линии электролюминесценции от температуры измерения и плотности тока накачки. Энергия (в эВ) максимума линии (113) дефекта с ростом температуры сдвигается в длинноволновую сторону параллельно уменьшению ширины запрещенной зоны и описывается формулой $E_{113}=907-0.49 T^{2} /(T+655)$. Интенсивность линии электролюминесценции с ростом температуры до $\sim 70 \mathrm{~K}$ при низких плотностях тока $\left(<2.59 \mathrm{~A} / \mathrm{cm}^{2}\right)$ возрастает с энергией возгорания 25 мэВ, а при больших плотностях не зависит от температуры. С увеличением температуры измерения интенсивность уменьшается с энергией гашения 59 мэВ, и линия регистрируется при $170 \mathrm{~K}$. Полуширина линии линейно возрастает с температурой: FWHM $=0.143 T+22.2$. Обнаружено уширение линии электролюминесценции по сравнению с линией фотолюминесценции. Использование методов инженерии дефектов позволяет предположить, что в ближайшее время будут созданы светодиодные структуры с электролюминесценцией (113) дефек- тов на длине волны $\sim 1370$ нм при комнатной температуре.

\section{Конфликт интересов}

Авторы заявляют, что у них нет конфликта интересов.

\section{Список литературы}

[1] G. Franzo, F. Priolo, S. Coffa, A. Polman, A. Carnera. Appl. Phys. Lett., 64, 2235 (1994).

[2] N.A. Sobolev, A.M. Emel'yanov, K.F. Shtel'makh. Appl. Phys. Lett., 71, 1930 (1997).

[3] V. Kveder, V. Badylevich, W. Schröter, M. Seibt, E. Steinman, A. Izotov. Phys. Status Solidi A, 202, 901 (2005).

[4] Н.А. Соболев, А.Е. Калядин, М.В. Коновалов, П.Н. Аруев, В.В. Забродский, Е.И. Шек, К.Ф. Штельмах, А.Н. Михайлов, Д.И. Тетельбаум. ФТП, 50, 241 (2016).

[5] S. Takeda. Jpn. J. Appl. Phys., 30, L639 (1991).

[6] L.I. Fedina, A.K. Gutakovskii, A.V. Latyshev, A.L. Aseev. In: Advances in Semiconductor Nanostructures, Growth, Characterization, Properties and Applications, ed by A. Latyshev, A. Dvurechenskii, A. Aseev (Elsevier, Amsterdam, 2016) p. 383.

[7] L. Jeyanathan, E.C. Lightowlers, V. Higgs, G. Davies. Mater. Sci. Forum, 143-147, 1499 (1994).

[8] S. Coffa, S. Libertino, C. Spinella. Appl. Phys. Lett., 76, 321 (2000).

[9] D.C. Schmidt, B.G. Svensson, M. Seibt, C. Jagadish, G. Davies. J. Appl. Phys., 88, 2309 (2000).

[10] Y. Yang, J. Bao, C. Wang, M.J. Aziz. J. Appl. Phys., 107, 123109 (2010).

[11] Н.А. Соболев, А.Е. Калядин, П.Н. Аруев, В.В. Забродский, Е.И. Шек, К.Ф. Штельмах, К.В. Карабешкин. ФТТ, 58, 2411 (2016).

[12] Н.А. Соболев, А.Е. Калядин, Е.И. Шек, К.Ф. Штельмах. ФТП, 51, 1182 (2017).

[13] N.A. Sobolev, A.E. Kalyadin, E.I. Shek, K.F. Shtel'makh, V.I. Vdovin, A.K. Gutakovskii, L.I. Fedina. Phys. Status Solidi A, 214, 1700317 (2017).

[14] J.F. Ziegler, M.D. Ziegler, J.P. Biersack. Nucl. Instrum. Meth. B, 268, 1818 (2010).

[15] V. Alex, S. Finkbeiner, J. Weber. J. Appl. Phys., 79, 6943 (1996).

[16] S. Binetti, S. Pizzini, E. Leoni, R. Somaschini, A. Castaldini, A. Cavallini. J. Appl. Phys., 92, 2437 (2002).

[17] Н.А. Соболев. ФТП, 44, 3 (2010).

[18] L. Xiang, D. Li, L. Jin, S. Wang, D. Yang. J. Appl. Phys., 113, 033518 (2013).

[19] G. Davies. Phys. Rep., 176, 83 (1989).

Редактор Л.В. Шаронова 


\section{Silicon light-emitting diodes with luminescence associated with (113) defects}

A.E. Kalyadin, K.F. Shtel'makh, P.N. Aruev, V.V. Zabrodskii, K.V. Karabeshkin, E.I. Shek, N.A. Sobolev

loffe Institute, 194021 St. Petersburg, Russia

Abstract Silicon light-emitting diodes with luminescence associated with (113) defects have been fabricated using implantation of $350 \mathrm{keV}$ oxygen ions at the dose of $3.7 \cdot 10^{14} \mathrm{~cm}^{-2}$ and subsequent annealing at $700^{\circ} \mathrm{C}$ for $1 \mathrm{~h}$ in a chlorine-containing atmosphere. Electroluminescence was studied in wide ranges of temperature and an excitation power. The line associated with (113) defects dominates in all the spectra. The temperature dependence of the line intensity depends on the excitation power in the range of low temperatures: an increase of the intensity with activation energy of $25 \mathrm{meV}$ is observed at low current density and, with the increasing current density, a rise of the intensity is not observed. At higher temperatures, a decrease of the intensity with activation energy of $59 \mathrm{meV}$ occurs regardless of a current density. With the increasing temperature, the peak of the line shifts by the same energy as the forbidden gap width, while the half width of the line grows linearly. 